\title{
ECZANE ÇALIŞANLARI TARAFINDAN KULLANILAN E-REÇETE SİSTEMİ BAŞARISININ ÖLÇÜLMESI
}

\author{
MEASURING THE SUCCESS OF E-PRESCRIPTION SYSTEM USED BY PHARMACY \\ PERSONNEL
}

\author{
Özel SEBETCI ${ }^{1}$ \\ Gökhan $\mathrm{AKSU}^{2}$ \\ Burçak ÖNDER ${ }^{3}$
}

\begin{abstract}
Öz
Ülkelerin kalkınma göstergelerinin başında sağlık düzeyiyle ilgili veriler gelmekte ve sağlık sistemini düzeltmek için verdikleri çabalar sağlık hizmetlerine yapılan değişimlerle mümkün olmaktadır. Bu değişimin başlıca yollarından biri, bilişim teknolojilerini kullanarak yapılan yatırımlardan oluşmaktadır. Türkiye'de sağlık hizmetinin geliştirilmesi ve memnuniyetin arttırılması kapsamında, 2013 yılının başından itibaren elektronik hizmetlerin geliştirilmesi ve bu sayede hizmet kalitesini arttırmayı hedeflemek için hastanelerin kullanmış oldukları bilgi sistemleri içinde yer alan elektronik reçete (e-reçete) uygulamasına geçilmiştir. E-reçete, eczanelerin, hekimlerin ve hastanelerin ortak kullanımına açılmış bir sistem üzerinden, hastanın bilgilerini içeren ve kâğıt kullanılmadan bu bilgilerin erişimine olanak sağlayan bir uygulamadır. Çalışmanın amacı; eczane çalı̧̧anlarının kullandıkları e-reçete sisteminin başarısının ölçümüdür. Çalışmanın sonucunda, kullanıcıların bu sistemden memnuniyet derecelerinin yüksek olduğu görülmektedir.
\end{abstract}

Anahtar Kelimeler: E-reçete, Hastane Bilgi Sistemi, Bilişim Sistemi Başarı Modeli

\begin{abstract}
Data on health levels are the primary development indicators for countries. Efforts made by governments to improve their health systems include transformations in health services. Investments made by using information technologies are one of the methods to perform these transformations. In an effort to enhance health services and increase satisfaction in Turkey, e-prescribing system (eRx) was initiated in Turkey in 2013 as a hospital information system to enhance electronic services and to increase service quality. E-prescribing application enables pharmacies, physicians and hospitals to access patient information over system that is open to joint use without using paper. The purpose of this study is to measure the success of e-prescribing system used by pharmacy personnel. We found that the users had high satisfaction levels from this system.
\end{abstract}

Key Words: E-prescription, Hospital Information System, Information System Success Model

\footnotetext{
${ }^{1}$ Yrd. Doç. Dr., Adnan Menderes Üniversitesi, MYO, Bilgisayar Programcılı̆̆ı, 0256 2145078,osebetci@adu.edu.tr

2 Öğretmen, Adnan Menderes Üniversitesi, MYO, Bilgisayar Programcılığı, gokhanaksu@adu.edu.tr

${ }^{3}$ Adnan Menderes Üniversitesi, Sosyal Bilimler Enstitüsü, Yüksek Lisans Öğrencisi, burcakonder@adu.edu.tr
} 


\section{GİRIŞ}

Günümüzde bilgi; ülkelerin zenginliğinin belirlenmesinde temel unsur olan, aynı zamanda ekonomik, sosyal ve kültürel gelişmelere katkı sağlayan itici bir güçtür (Turan, Çolakoğlu, 2008:107). Son yıllarda bilim ve teknolojide meydana gelen hızlı değişim ve gelişmeler iletişim ve bilgi teknolojilerini de önemli ölçüde etkilemektedir. Bu değişim ve gelişmeler bilginin üretilmesini, paylaşılmasını ve kullanılmasını hızlandırmış, bilgi, eğitimde olduğu kadar, kamu hizmetlerinde de temel belirleyici faktör olmuştur (Tor, Erden, 2004:120).

Bilgi teknolojileri, diğer bütün sektörleri etkilediği gibi sağlık sektörünü de etkilemiştir (Gelatti vd., 2013). Bilgi teknolojisi, sağlık bakım ve hizmetlerini geniş bir alanda desteklemek için kullanılmaktadır (Chen, Hsiao, 2011).Sağlık kuruluşları günümüzde bilişim sistemlerinden, hastalıkların teşhisi, hekimlerin hastayla ilgili verecekleri karmaşık konularda karar desteği, bu açıdan hemşire ve hekimlere yol göstermesi, laboratuvar hizmetleri ve hasta yönetimi gibi çok çeşitli alanlarda birçok sistemden faydalanmaktadır (Özata, Aslan, 2004). Sağlık sektöründe,klinik verilerin toplanmasını sağlayan, bu verileri koruyan, istatistiksel analizlerini hastane bilgisayar ağ sistemi yöntemiyle yöneten bazı ülkelerde de olgun örnekleri mevcut olan Hastane Bilgi Sistemi yer almaktadır (HBS). (Hong-Sun, Zang, 2012). HBS, hasta bakım süreçleri altında yer alan randevu planlaması, hasta kabulü, muayene, tedavi gibi hizmetleri yönetmek için tasarlanmış bir bilgi sistemidir. HBS uygulaması; daha iyi hasta güvenliği, finansal yönetim, kapsamlı klinik sistem ve elektronik sağlık karnesi gibi avantajlar sağlar (Yucel vd., 2011). HBS kullanımı, sağlık ortamında hataların azaltılması bakımından önemli bir araçtır (Khokhar vd., 2013). Ülkemizde de son on yılda birçok devlet hastanesi HBS'yi hayata geçirmiştir. Uygulamalarda yanlış kullanımlar, aşırı ve yasadışı kullanım nedeniyle kayıplar, hatalar sebebiyle HBS uygulaması daha iyi bir hasta bakımı sağlamıştır (Yücel, 2011).

Hastanelerde hasta tıbbi bakımı belirli ölçüde bireyselleştirilmiş ilgi gerektirir ve bu amaçla teknolojik destek daha gerekli hale gelmektedir. Bu yüzden hasta güvenliğinde önemli faktörler olabileceği dikkate alınarak HBS içerisinde yeni teknoloji uygulaması olarak elektronik reçete (e-reçete) sistemi ortaya konmuştur ve bu sistemle reçeteli ilaç kullanımı işlemlerinde güvenliği garanti altına almak ve ilaç hatalarını azaltmak amaçlanmaktadır(Villamanan vd., 2010). Bu teknolojiyle, sistemi kullananlar elektronik sağlık kaydı üzerinden sisteme giriş yapıp, değişiklikleri ve görüşlerini yazabilmektedirler. Birinci basamak sağlı hizmetlerinde ilaç kullanımıyla ilgili birçok sorun meydana 
gelmektedir ve bu nedenle, bu basamakta e-reçete kullanımını arttırmak için son on y1lda yapılan büyük yatırımlar olmuştur (Motulsky vd., 2013). Bu sistem, ilaçların güvenli ve zamanında tedariğini, birçok tedavi edilebilir kronik koşuldaki hastaların ilaç kullanım seviyesini belirler, aynı zamanda kullanıcılar açısından önemli bir zaman tasarrufu ve verimlilik artışı sağlar (Lichtner vd., 2013).

$\mathrm{Bu}$ çalışmanın amacı; sağlık alanında hizmet verenlerin HBS ile entegre çalışan ereçete sisteminin başarısının ölçümüdür. Bilişim Sistemleri başarısının ölçümünde DeLone ve McLean'in (2003) Güncellenmiş Bilişim Sistemleri Başarı Modeli üzerine geliştirilmiş Klinik Bilgi Sistemleri Başarı Modeli kullanılmıştır (Smith, Effken, 2013).

\section{KAVRAMSAL ÇERÇEVE}

\subsection{Hastane Bilgi Sistemleri ve E-Reçete}

Sağlık alanında oluşan iş hataları ve hasta güvenliği konuları, sağlık ağlarının gelişmesinde ayrı bir önem kazanmaktadır (Ball, 2003).Hastaneler de yüksek düzeyde bilgi yoğun örgütler olduklarından, teknolojik gelişmeler sayesinde bilgilerin toplanması, depolanması, iletilmesi, işlenmesi gibi uygulamalarla düşük maliyet açısından hastane yönetiminde özel bir sistem uygulanmaktadır. HBS, sağlık uygulayıcıları tarafından izlenebilen bir sistemdir ve aynı zamanda ilaçların otomatik siparişi, ilaç yasakları, hasta hizmetleri gibi alanlarda etkin olarak kullanılmaktadır(Borzekowski, 2009). HBS, günlük tıbbi hizmetlerin iş akışını işleyen, mali, idari ve klinik verilerin yönetimini kolaylaştıran bir bilgisayar sistemidir (Liu vd., 2006). HBS içerisinde yer alan uygulamalardan bir tanesi olan e-reçete tanım olarak, bilgisayar sistemi üzerinden bilgilerin girilmesi, değiştirilmesi, gözden geçirilmesi ve iletişim kurulması için kullanılan bir teknolojidir, bununla beraber sistemin ilk odak noktası da verilen kararlara destek ve tutulan hasta kaydıyla elektronik bilgilerin reçete kalitesini arttırmaktır (Motulsky, 2013).Bazı eczacıların reçete bilgilerine çeşitli yollarla (örneğin hastaya sorarak veya reçeteyi yazanı arayarak) erişimlerini sağlarlarken, onların genellikle bunu yapmak için yeterli zamanları ve fırsatları olmamakta, aynı zamanda bilgilerin doğruluğu çoğu zaman şüpheli ve eksik olmaktadır (Warholak, 2014). Reçeteli ilaçların yanlış kullanımı, birçok hastanın fiziksel ve ruhsal sağlık sorunlarıyla da alakalı önemli bir halk sağlı̆gı sorunudur (Kelly vd., 2013). Sorunların bazıları, hasta güvenliği sorunu, bazıları da üretkenlik ve iş akışı verimliliği sorunudur. Bu sebeple, hastabulgularının eklenmesiyle eczacılar tarafında da karışıklık ve belirsizlik azaltılmaktadır ve böylece e-reçete kullanıcıları arasındaki (hekimler, eczacılar) müdahale ve temas sayıları da bu sayede azalmaktadır (Warholak vd., 2014).E-reçete sistemi, sağlık ayarlarında bu tür etkileri ortadan 
kaldırmak için yeni sağlık bilgi teknolojisi olarak hayata geçirilmiştir. Özellikle e-reçete, ilaç hatalarının endişe verici bir sonucu olarak ortaya çıkmıştır ve toplumda rahatsızlık uyandıran bu hataların ortadan kaldırılması ve hasta güvenliğini sağlaması bakımından bir araç olarak kabul edilmiştir (Odukoya vd., 2013).

\subsection{Bilgi Sistemleri Başarı Modeli}

DeLone ve McLean, teknolojinin ve kullanıcı ihtiyaçlarının zamanla değişmesi sonucunda, bilgileri daha verimli kullanabilmek açısından Bilgi Sistemleri Modeli'ni ortaya çıkarmışlardır (DeLone, McLean, 1992). DeLone ve McLean, Bilgi Sistemleri Başarı anlayışımıza kapsamlı bir incelemeyle ölçümler yaparak önemli katkılar sağlamışlardır. $\mathrm{Bu}$ katkılar, modele altı kategori (bilgi kalitesi, sistem kalitesi, kullanım, kullanıcı memnuniyeti, bireysel etki ve örgütsel etki) ekleyerek bu kategoriler arasında karşılıklı dayanışmayı sağlayan bir model önermişlerdir (Seddon, Kiew, 1996). DeLone\&McLean Başarı Modeli'nde kullanıcılar üzerindeki bilginin etkisi, modelin etkililik düzeyini gösterir, aynı zamanda modeldeki faktörlerden sistem kalitesi, teknik başarı; bilgi kalitesi, anlamsal başarı; kullanım, kullanıcı memnuniyeti, bireysel ve örgütsel etkiler de etkinlik açısından başarı anlamına gelmektedir (DeLone, McLean, 2003).DeLone ve McLean, kendilerine özgü modeli bir on yıl üzerinde daha yansitarak (DeLone, McLean, 2003), teknolojideki değişiklikleri ve kullanıcı ihtiyaçlarını da gözönünde bulundurup, modellerinde çeşitli ve önemli değişiklikler yapmışlardır. DeLone ve McLean, bireysel, örgütsel, sanayi ve toplumsal etkileri 'net fayda' içinde birleştirmiş ve 'hizmet kalitesi'ni orijinal modellerine dahil etmişlerdir (Wong, 2011).

DeLone ve McLean'in, güncelleştirilmiş modellerine yaptıkları son bir geliştirme ile kullanım yapısına başka bir açıklama inşa etmişlerdir. Öncelikli olarak kullanıcı memnuniyeti bir süreç olarak kullanılmalıdır, olumlu deneyimlerle 'kullanım', nedensel bir anlamda 'kullanıcı memnuniyeti'ne yol açacaktır (DeLone, McLean, 2003). Daha sonra kullanımı etkileyecek olan kullanım niyeti, daha yüksek bir kullanıcı memnuniyetini beraberinde getirecektir. Aynı zamanda DeLone ve McLeanModeli'nin, bilgi teknolojileri başarı ölçümlerini düzenlemek için yararlı olduğu bulunmuştur ve bu model bilgi teknolojileri araştırmacıları tarafından, bilgi teknolojisi başarısının anlaşımı ve ölçümü için kullanılmaktadır (Petter vd., 2008).

DeLone\&McLean Modeli üzerine geliştirilen Klinik Bilgi Sistemleri (KBS) Modeli'nde, sağlık çalışanları perspektifinden, sosyal etki ve kolaylaştırıcı durum faktörleri de eklenerek, çalışanların sistemden memnuniyet düzeylerinin ölçülmesi amaçlanmaktadır. 
(Smith, Effken, 2013).KBS'nin, hastanın veri almasına daha iyi erişilebilirlik ve iletişimde verimliliği sağladığına inanılmaktadır (Smith vd., 2005). KBS’nin yüksek düzeyde kullanıcı direnci olmasına rağmen, bu sistem genellikle hızlı bilgi ve etkin veri yönetimi ile yüksek kaliteli bakım sunmak için etkin bir araç olarak teşvik edilmektedir (Meijden vd., 2003). Gelişmiş sağlık hizmetleri için başarılı bir KBS uygulama anlayışı bu nedenle önemlidir (Lehoux, Denis, 1999).

KBS'yi genel olarak değerlendirdiğimizde, KBS kullanıcılarının yer aldığı boyutların bulunduğu güvenilir modele ihtiyaç duyulduğu açıkça görülmektedir (Gros vd., 2005). KBS üzerine yapılan yatırımlar, kuruluşların bilgi sistemlerinin kullanımındaki etkinliğini sağlamak içindir ve bu sistemin başarısının en önemli belirleyicisi kullanıcıların memnuniyetinin yerine getirilmesidir (Aggedilis, Chatzoglou, 2012).

\subsection{Literatür}

Sağlık alanında Bilişim Sistemleri Modeli üzerine çalışmalar yapan araştırmalar bulunmaktadır. Mevcut modellerin iyileştirilerek uygulandığı çalışmalar aşağıdaki gibi referans gösterilerek belirtilmiştir.

Torkzadeh ve Doll'un (1999), bilgi teknolojilerinin etkisi hakkındaki algıları ölçmek için geliştirdikleri araçlarında, bireyin çalışma düzeyinde teknolojinin birden fazla etkileri olduğunu belirtirler. Bu çalışma, bilgi teknolojisi etkisini geniş bir şekilde tasvir ederek, bilişim sistemlerinin bireyler tarafından nasıl kullanıldığını açıklar. Çalışmalarında, bilgi teknolojisini kapsamlı olarak ölçen 4 maddenin belirleyici olduğunu, bunların da görevdeki verimlilik ve yenilikler, kullanıcı memnuniyeti ve yönetim kontrolünden oluştuğunu belirtmektedirler. Sonuçların da 4 faktör modelini desteklediği görülmüştür.

Chadwick ve New'in (2003) çalışması, bir hastanede yatan diyabet hastalarının, onların uzak bir alanda çalışan gözlükçülere ulaşmalarını sağlayan internet erişimli bir sistemi anlatmaktadır. Bu sisteme ulaşmak için standart bir web tarayıcısı kullanarak diabet bilgi sistemlerini (DIS) geliştirmişlerdir. Sistem, doktorların internet veri güvenliğini sağlamak için güçlü şifreleme ve dijital imzalı mesajları ile bir ortak anahtar altyapısını kullanmaktadır. $\mathrm{Bu}$ iyi tasarlanmış sistemde araştırmacılar, maliyetler ve elektronik uygulamanın yararlarını kullanıcı memnuniyeti açısından ölçmüşlerdir. Bu sistemin, gözlükçülere hastaların son verilerine ulaşım imkanı vererek, hasta bakımını geliştirmeye yardımcı olabileceğini öne sürmüşlerdir. 
Gros ve Lovis'in (2004), KBS ile çalışanlar üzerinde yaptıkları araştırmada kullanıcılar için DeLone\&McLean Modeli (1992), TAM (TecknologyAcceptance Model) ve TTF (TaskTecnologyFit), birleştirerek bir model önermişlerdir. Bu modelde geleneksel KBS boyutlarını kapsayan insan-bilgisayar etkileşimli sekiz anahtar değişkenin (Acceptance, crossed, affectiveresponse, evauation in general, impact, satisfaction, success, TTF) tanımlanmasına yol açan kullanıcı memnuniyetinin, başarı için en çok kullanılan referans olduğu ortaya konulmuştur.

Aggelidis ve Chatzoglou'nun (2012), hastane bilgi sistemlerinde bilgisayar kullanıcılarının memnuniyetinin ölçüldüğü araştırmalarında, kuruluşların bilgileri etkin kullanmalarının, yaptıkları yatırımlara bağlı olduğunu öne sürerlerken, kullanıcı memnuniyetinin bu sistem üzerinde en önemli belirleyici faktör olduğunu belirtmişler ve bu modelde End-User Computing Satisfaction(EUCS) geçmiş modelleri test edip, hastane bilgi sistemi kullanıcıları arasında memnuniyetin nasıl oluştuğunu yeni kavramsal perspektifler önererek ilgili bilginin üzerine inşa etmişlerdir.

Smith ve Effken(2013), KBS başarısının hemşire perspektifinden değerlendirilmesi bakımından Klinik Bilgi Sistemleri Başarı Modeli’ni geliştirmişlerdir. 4 ayrı hastanede gerçekleştirdikleri araştırmada KBS modelini sosyal etki ve kolaylaştırıcı durumları da dahil ederek sistemin kullanımının hemşireler üzerindeki kullanıcı memnuniyetini ölçmeyi amaçlamışlardır. Bunun sonucunda kolaylaştırıcı durumlar memnuniyeti doğrudan etkilerken, sosyal etkinin hemşire memnuniyeti üzerinde önemli bir etkisinin olmadığını öne sürmüşlerdir.

\section{ARAŞTIRMANIN AMACI VE HIPOTEZLERI}

Çalışmanın amacı; sağlık alanında hizmet veren eczane çalışanlarının e-reçete sisteminden memnuniyet düzeylerinin ölçülmesidir. Bu ölçümü gerçekleştirebilmek için Bilişim Sistemleri Başarı Modeli üzerine geliştirilmiş Klinik Bilgi Sistemleri (KBS) Modeli uygulanmıştır. Çalışmanın hipotezleri aşağıda belirtilmiştir. Modeldeki değişkenler; Bilgi Kalitesi (BK), Sistem Kalitesi (SK), Kullanım Bağımlılığı (KB), Kullanıcı Memnuniyeti (KM), Sosyal Etki (SE), Kolaylaştırıcı Durumlar (KD) ve Net Fayda (NF)'dır. Araştırmanın hipotezleri aşağıdaki şekilde oluşturulmuştur.

H1a: Sağlık kurumlarında çalışan eczacıların e-reçete sistemi kullanımındaki Bilgi Kalitesi (BK), Kullanıcı Memnuniyetini (KM) doğrudan ve olumlu etkiler. 
H1b: Sağlık kurumlarında çalışan eczacıların e-reçete sistemi kullanımındaki Bilgi Kalitesi (BK), Kullanım Bağımlılığını (KB) doğrudan ve olumlu etkiler.

H2a: Sağlık kurumlarında çalışan eczacıların e-reçete sistemi kullanımındaki Sistem Kalitesi (SK), Kullanıcı Memnuniyetini (KM) doğrudan ve olumlu etkiler.

H2b: Sağlık kurumlarında çalışan eczacıların e-reçete sistemi kullanımındaki Sistem Kalitesi (SK), Kullanım Bağımılılığını (KB) doğrudan ve olumlu etkiler.

H3a: Sağlık kurumlarında çalışan eczacıların e-reçete sistemi kullanımındaki Sosyal Etki (SE), Kullanıcı Memnuniyetini (KM) doğrudan ve olumlu etkiler.

H3b: Sağlık kurumlarında çalışan eczacıların e-reçete sistemi kullanımındaki Sosyal Etki (SE), Kullanım Bağımlılığını (KB) doğrudan ve olumlu etkiler.

H4a: Sağlık kurumlarında çalışan eczacıların e-reçete sistemi kullanımındaki Kolaylaştırıcı Durumlar (KD), Kullanıcı Memnuniyetini (KM) doğrudan ve olumlu etkiler.

H4b: Sağlık kurumlarında çalışan eczacıların e-reçete sistemi kullanımındaki Kolaylaştırıcı Durumlar (KD), Kullanım Bağımlılığını (KB) doğrudan ve olumlu etkiler.

H5a: Sağlık kurumlarında çalışan eczacıların e-reçete sistemi kullanımındaki Kullanıcı Memnuniyeti (KM), Net Faydayı (NF) doğrudan ve olumlu etkiler.

H5b: Sağlık kurumlarında çalışan eczacıların e-reçete sistemi kullanımındaki Kullanım Bağımlılığı (KB), Net Faydayı (NF) doğrudan ve olumlu etkiler.

Araştırma kapsamında oluşturulan hipotezlerin test edilmesiyle amacıyla değişkenler arası ilişkileri gösteren model Şekil 1'de verilmiştir.

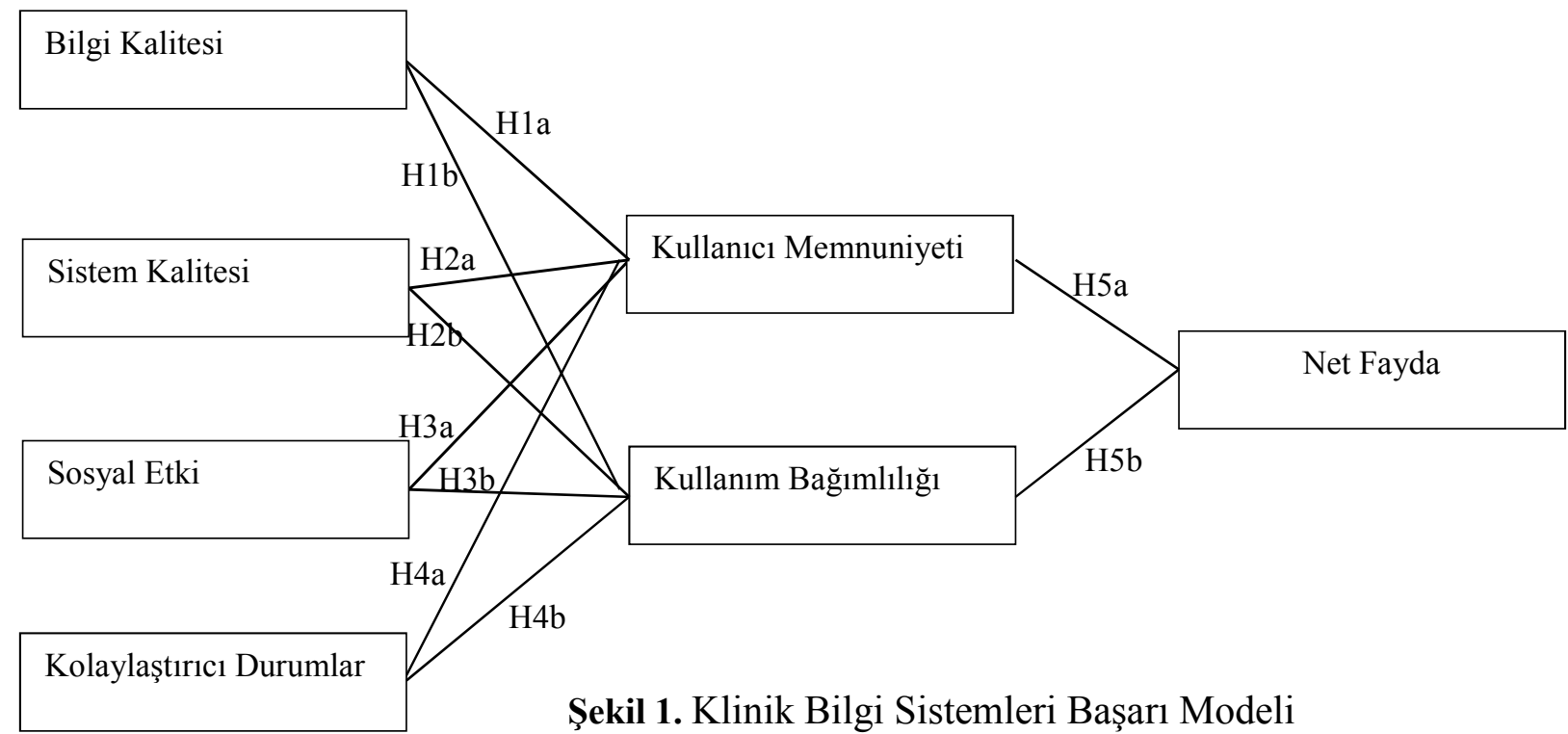




\section{ARAŞTIRMANIN YÖNTEMİ VE BULGULARI}

Araştırma kapsamında, bilgi teknolojileri literatüründe daha önceden geliştirilip kullanılmış olan ölçeklerden faydalanılmış olup, anket soruları eczane çalışanları kapsamında uyarlanarak 5'li Likert tipinde hazırlanmıştır (1:Hiç Katılmıyorum, 2: Katılmıyorum, 3: Az Katılıyorum, 4: Katılıyorum, 5:Kesinlikle katılıyorum). Bilgi Kalitesi sorular1;Somers, Nelson ve Karimi(2003), Roy, Bouchard (1999),Downing'den (1999), Sistem Kalitesisoruları;Petter, Fruhling (2011), Goodhue, Thompson (1995), Kullanım Bağımlılığı soruları; Chang'den (2010), Kullanıcı Memnuniyeti soruları; Paul, Patrick, Chau, Shang ve Tam (1999), Ong, Lai (2007), Palvia'dan (1999), Sosyal Etki soruları; Torkzadeh (1999), Aggedilis, Chatzoglou (2012), Sundaravej'den (2013),Kolaylaştırıcı Durum soruları; Torkzadeh (1999), Abdulwahab, Zulkhairi'den (2010), Net Fayda soruları; Praybutok, VR. (2008), Raghavan'dan(2010) uyarlanarak hazırlanmıştır. Betimsel bir çalışma yapılan araştırma, tarama modellerinden genel tarama modellerine uygundur.

\subsection{Evren ve Örneklem}

Araştırmanın evrenini Aydın ilinde hizmet veren tüm eczane çalışanları oluşturmaktadır. Araştırmada dağıtılan anket formlarının doldurulması gönüllülük esasına dayanmaktadır. İl Sağlık Müdürlüğü ve diğer resmi makamlardan gerekli izinler alınarak hazırlanan anket formundan 113 tanesi eczacı ve eczane çalışanları tarafindan doğru olarak kodlandığı belirlenerek çalışma örneklemine alınmıştır. Çalışma 2013 yılının ekim ve kasım aylarında gerçekleştirilmiştir.

\subsection{Veri Toplama Araçları}

Çalışmada eczacılık sektöründe çalışanların kullandıkları e-reçete programına ilişkin algıladıkları net faydayı ve bunun araştırmanın bağımsız değişkenleri tarafından ne düzeyde açıklandığını belirlemek amacıyla ilgili literatür taraması sonucunda Bilgi Kalitesi, Sistem Kalitesi, Sosyal Etki, Kolaylaştırıcı Durumlar, Kullanıcı Memnuniyeti, Kullanım Bağımlılığıve Net Fayda boyutlarını ölçen test maddelerinin hangi araştırmacılar tarafından geliştirildiği ve araştırmada hangi soruların ilgili boyutta yer aldığı Tablo 1'de gösterilmiştir. 
Tablo 1. Araştırmada Kullanılan Soru Maddeleri ve Açıklamaları

\begin{tabular}{lll}
\hline ÖLÇEKLER & SORULAR & KAYNAKLAR \\
\hline Bilgi Kalitesi (IQ) & $(1,2,3,4,5,6)$ & $(9,30,31,35)$ \\
\hline Sistem Kalitesi (SYQ) & $(20,21,22,23,24,25,26,27,28)$ & $(12,28)$ \\
\hline Kullanım Bağımlıı̆̆ (UD) & $(45)$ & $(5)$ \\
\hline KullanıcıMemnuniyeti (US) & $(38,39,40,41,42,43,44)$ & $(23,25,26)$ \\
\hline Sosyal Etki (SI) & $(7,8,9)$ & $(2,37)$ \\
\hline KolaylaştırıcıDurumlar (FC) & $(10,11,12,13,14,15,16,17,18,19)$ & $(1,37)$ \\
\hline Net Fayda (NB) & $(46,47,48,49,50)$ & $(29,30)$ \\
\hline
\end{tabular}

Araştırma kapsamında tasarlanan modelin test edilmesi amacıyla ilgili literatür taraması sonucu belirlenen boyutların araştırmanın çalışma grubu tarafindan desteklenip desteklenmediğini belirlemek ve ölçme aracının faktör yapısını belirlemek amacıyla Varimax dik döndürme yöntemi kullanılarak ölçme aracının boyutları belirlenmiştir. Analiz sonucu elde edilen bulgular Tablo 2'de gösterilmiştir.

\subsection{Verilerin Analizi}

Araştırmanın 1. ve 2. alt problemlerinde değişkenler arasında ilişki olup olmadığını belirlemek amacıyla korelasyon analizi kullanılmıştır. Araştırmanın 3. alt probleminde bağımsız değişkenlerden analitik ve mantıksal düşünme yeteneklerinin bağımlı değişken olan programlama başarısını ne düzeyde yordadığını saptamak amacıyla çok değişkenli regresyon analizi kullanılmıştır. Bağımsız değişkenlerden hangilerinin programlama başarısına anlamlı bir katkı sağladığını belirlemek amacıyla aşamalı regresyon (stepwise) yöntemi uygulanmıştır. Araştırmada 4. ve 5. alt problemlerin sınanması için öncelikle verilerin normallik ve homojenlik varsayımını sağlayıp sağlamadığı test edilmiştir. Normallik testi için Kolmogorov-Smirnov testi uygulanmıştır. Bu test sonucunda elde edilen değer $(\mathrm{p}>.05)$ verilerin çalışma evreninde normal dağılım gösterdiği ve bu nedenle parametrik analiz yöntemlerinin uygulanmasına karar verilmiştir. Grupların varyanslarının homojen olup olmadığını belirlemek amacıyla Levene testinden yararlanılmıştır. Varyansların homojenliği durumunda ise Tukey's testine başvurulmuştur. Çalışmada grup sayısına bağlı olarak iki grubun karşılaştırılmasında bağımsız örneklem t-testi, üç grubun karşılaştırılmasında ise tek yönlü varyans analizi (ANOVA) kullanılmıştır. Araştırma kapsamında yapılan analizlerde SPSS 19 paket programından yararlanılmıştır.

\subsection{Bulgular}

Çalışmanın bu bölümünde elde edilen bulgular; araştırmada yer alan değişskenlerin betimsel analizi sonucu elde edilen frekans ve yüzde değerleri, gözlenen değişkenler arasındaki korelasyon analizi sonuçları, araştırmada kullanılan ölçekle ilgili bulgular ve 
araştırma kapsamında geliştirilen modele ilişkin çoklu regresyon analizi sonuçları olarak belirlenmiştir. Tablo 1'de araştırmaya dahil olan sağlık çalışanlarının demografik özellikleri verilmektedir.

Tablo 1. Sağlık Çalışanlarının Demografik Özellikleri

\begin{tabular}{|c|c|c|c|c|c|c|c|}
\hline Değişkenler & & $\mathrm{n}$ & $\%$ & Değişkenler & & $\mathrm{n}$ & $\%$ \\
\hline \multirow[b]{2}{*}{ Cinsiyet } & Kadın & 40 & 35,6 & \multirow{5}{*}{$\begin{array}{l}\text { Eğitim } \\
\text { Durumu }\end{array}$} & Lise & 50 & 44,2 \\
\hline & Erkek & 73 & 64,4 & & Yüksekokul & 9 & 8,0 \\
\hline \multirow{3}{*}{ Yaş } & 25 den az & 8 & 7,1 & & Üniversite & 52 & 46,0 \\
\hline & $25-40$ aras 1 & 63 & 55,8 & & Yüksek Lisans & 1 & 0,9 \\
\hline & $41-55$ aras 1 & 36 & 37,1 & & Doktora & 1 & 0,9 \\
\hline \multirow{4}{*}{$\begin{array}{c}\text { Çalış̧ma } \\
\text { Süresi }\end{array}$} & $0-5$ aras1 & 12 & 10,6 & \multirow[t]{4}{*}{$\begin{array}{l}\text { Mesleki } \\
\text { Ünvan }\end{array}$} & Eczacı & 54 & 47,8 \\
\hline & $6-10$ aras1 & 21 & 18,6 & & Eczac1 Kalfası & 59 & 52,2 \\
\hline & $11-16$ aras 1 & 35 & 31,0 & & & & \\
\hline & 16 ve üzeri & 45 & 39,8 & & & & \\
\hline
\end{tabular}

Tablo 1.'de görüldüğü üzere, 113 sağlık çalışanının \% 35,6'sının cinsiyeti kadın ve \%64,4'ünün cinsiyeti erkektir. Çalışanların yaş dağılımları incelendiğinde \%7,1'inin 25 yaşın altında, \%55,8'inin25-40 yaş aralığında, \%37,1'inin 41-55 yaş aralığında yer almaktadır. Sağlık çalışanlarının sektörde çalışma sürelerine göre dağılımları incelendiğinde çalışanların \%10,6'sının0-5 y11, \%18,6'sinın 6-10 y11, \%31'inin 11-16y1l ve \%39,8'inin 16 ve daha uzun süredir sektörde çalıştı̆̆ 1 tespit edilmiştir.Araştırmaya katılanların eğitim durumlarına göre dağılımları incelendiğinde \%44,2'sinin lise, \%8'inin yüksekokul, \%46'sının üniversite, \%0,9'unun yüksek lisans ve \%0,9'unun doktora mezunu olduğu belirlenmiştir. Araştırmada ayrıca çalışanların unvanlarına göre dağılımları \%47,8 eczacı ve \%52,2 eczacı kalfası olarak tespit edilmiştir. Araştırmada 50 maddeden oluşan ankette yer alan soruların hangi faktörler altında toplandığını belirlemek amacıyla faktör analizi uygulanmıştır. Yapılan faktör analizi sonucunda elde edilen Kaiser-Meyer-Olkin (KMO) değeri .88 ve Barlettküserellik test değeri=5080,75; p=,000 olarak hesaplanmıştır. Elde edilen bu değer verilerin faktör analizi için uygun olduğunu göstermektedir. 
Tablo 2. Açıklayıcı Faktör Analizi Sonuçları

\begin{tabular}{|c|c|c|c|c|}
\hline E-REÇETE SİSTEMINE İLIŞKİN SORULAR & $\begin{array}{c}\text { Cronbach } \\
\text { Alpha }\end{array}$ & $\begin{array}{l}\text { Faktör } \\
\text { Yükleri }\end{array}$ & $\begin{array}{c}\text { Öz Değer } \\
(\%)\end{array}$ & $\begin{array}{c}\text { Toplam } \\
\text { Varyans }(\%)\end{array}$ \\
\hline \multicolumn{5}{|l|}{ Faktör 1 - Sistem Kalitesi } \\
\hline Soru20 & .910 & .836 & 18,64 & 18,64 \\
\hline Soru21 & & .833 & & \\
\hline Soru22 & & .802 & & \\
\hline Soru23 & & .782 & & \\
\hline Soru24 & & .762 & & \\
\hline Soru 25 & & .740 & & \\
\hline Soru26 & & .722 & & \\
\hline Soru 27 & & .674 & & \\
\hline Soru28 & & .625 & & \\
\hline \multicolumn{5}{|l|}{ Faktör 2 - Bilgi Kalitesi } \\
\hline$\overline{\text { Soru1 }}$ & .881 & .730 & 12,18 & 30,82 \\
\hline Soru2 & & .662 & & \\
\hline Soru3 & & .580 & & \\
\hline Soru4 & & .574 & & \\
\hline Soru5 & & .561 & & \\
\hline Soru6 & & .559 & & \\
\hline \multicolumn{5}{|l|}{ Faktör 3 - Kolaylaştırıcı Durumlar } \\
\hline$\overline{\text { Soru10 }}$ & .816 & .754 & $\mathbf{1 0 , 0 3}$ & 40,85 \\
\hline Soru11 & & .744 & & \\
\hline Soru12 & & .630 & & \\
\hline Soru13 & & .628 & & \\
\hline Soru14 & & .576 & & \\
\hline Soru15 & & .554 & & \\
\hline Soru16 & & .521 & & \\
\hline \multicolumn{5}{|l|}{ Faktör 4 - Sosyal Etki } \\
\hline Soru7 & .805 & .824 & 7,05 & 47,90 \\
\hline Soru8 & & .668 & & \\
\hline Soru9 & & .475 & & \\
\hline \multicolumn{5}{|l|}{ Faktör 5 - Kullanıcı Memnuniyeti } \\
\hline Soru38 & .793 & .648 & 4,22 & 52,12 \\
\hline Soru39 & & .606 & & \\
\hline Soru40 & & .598 & & \\
\hline Soru41 & & .540 & & \\
\hline Soru42 & & .512 & & \\
\hline Soru43 & & .504 & & \\
\hline Soru44 & & .497 & & \\
\hline \multicolumn{5}{|l|}{ Faktör 6 - Kullanım Bağımlılığı } \\
\hline$\overline{\text { Soru45 }}$ & .786 & .875 & 2,62 & 54,74 \\
\hline \multicolumn{5}{|l|}{ Faktör 7 - Net Fayda } \\
\hline Soru46 & .782 & .759 & 2,18 & 56,92 \\
\hline Soru47 & & .712 & & \\
\hline Soru48 & & .624 & & \\
\hline Soru49 & & .574 & & \\
\hline Soru50 & & .561 & & \\
\hline Toplam & .877 & & & 56,92 \\
\hline
\end{tabular}

Anket yardımıyla elde edilen verilere temel bileşenler analizi ve varimax dik döndürme yöntemi ile yapılan faktör analizi sonucu 50 maddenin öz değeri 1,00'den büyük olan 7 faktör altında toplandığı tespit edilmiştir. Dolaysıyla ölçme aracının 7 faktör yapısına 
sahip olduğu görülmüştür. Sistem Kalitesi, Bilgi Kalitesi, Kolaylaştırıcı Durumlar, Sosyal Etki, Kullanıcı Memnuniyeti, Kullanım Bağımlılı̆̆ı ve Net Fayda olmak üzere 7 faktörlü yapının toplam varyansının \%56,92'sinin değişkenler tarafından açıklandığı belirlenmiştir. Faktör analizi sonucu elde edilen toplam varyansın yüksek olması ölçeğin faktör yapısının da güçlü olduğunu göstermektedir. Elde edilen bu sonuç, test maddelerinin faktör yapısının alanyazında yapılan çalışmalar ile uyumlu olduğunu göstermektedir. Ölçeğin faktör yapısını belirledikten sonra araştırmacılar tarafından geliştirilen modelin test edilmesi amacıyla araştırmanın örtük değişkenleri arasındaki ilişkilerin belirlenmesi amacıyla Pearson Korelasyon Katsayıları hesaplanmış ve elde edilen değerler Tablo 3 'te gösterilmiştir.

Tablo 3. Araştırmanın Gözlenen Değişkenleri Arasındaki Korelasyon Analizi Sonuçları

\begin{tabular}{|c|c|c|c|c|c|c|c|}
\hline Değişkenler & (1) & (2) & (3) & (4) & $(5)$ & (6) & (7) \\
\hline \multicolumn{8}{|l|}{ 1. Sistem Kalitesi } \\
\hline 2. Bilgi Kalitesi & $.50 * *$ & & & & & & \\
\hline 3. Kolaylaştırıcı Durumlar & $.59 * *$ & $.59 * *$ & & & & & \\
\hline 4. Sosyal Etki & $.39 * *$ & $.76^{* *}$ & $.53 * *$ & & & & \\
\hline 5. Kullanıcı Memnuniyeti & $.63 * *$ & $.74 * *$ & $.72 * *$ & $.64 * *$ & & & \\
\hline 6. Kullanım Bağımlılı̆g & $.49 * *$ & $.73^{* *}$ & $.47 * *$ & $.72 * *$ & $.73 * *$ & & \\
\hline 7. Net Fayda & $.53 * *$ & $.68 * *$ & $.50 * *$ & $.68^{* *}$ & $.79 * *$ & $.83 * *$ & \\
\hline
\end{tabular}

Araştırmanın bağımsız değişkenleri arasındaki ilişkiler incelendiğinde tüm ilişkilerin .01 düzeyinde anlamlı olduğu görülmektedir. Ayrıca araştırmacılar tarafından geliştirilen modelde bağımsız değişkenler; sistemin özel fonksiyonlarının kullanışlılığı, sistemin güvenilirliliğini ve esnekliğini belirten (DeLone\&McLean, 1992) Sistem Kalitesi, anlayışın kolaylaştırılmasını sağlayan, güvenlik ve ilişki kurulmasını ifade eden (Floropoulos vd. 2010) Bilgi Kalitesi, kullanıcının kişisel deneyimi ve yaşıyla desteklenen (Vencatesh, 2003) Kolaylaştırıcı Durumlar ve bireyin diğerlerinden sistem hakkında edindiği bilgileri onun yeni geliştirilen sistemi kullanıp kullanmaması algısını ifade eden (LongLi, 2013) Sosyal Etki (SE) olarak belirlenmiştir. Araştırmanın bağımsız değişkenlerinin memnuniyet düzeyini (Smith, Effken, 2013) belirten Kullanıcı Memnuniyetini (KM) ve klinisyenlerin çalışma rutinine entegre olma düzeyini (Goodhue, Thompson, 1995) ifade eden Kullanım Bağımlılığını (KB) etkilediği kabul edildiğinden Kullanıcı Memnuniyeti ve Kullanım Bağımlılı̆̆ı araştırmanın bağımlı değişkenleri olarak belirlenmiştir. Daha sonra Kullanıcı Memnuniyeti ve Kullanım 
Bağımlılığının Net Faydayı ne düzeyde etkilediği geliştirilen modelle test edilmiştir. Bu modelde bağımsız değişkenler arasındaki korelasyon katsayısının .90 değerinden daha düşük olması değişkenler arasında çoklu bağıntılılık probleminin olmadığını göstermektedir (Büyüköztürk, 2010). Tablo 3'de Bilgi Kalitesi ile Sistem Kalitesi arasında pozitif yönde ve orta düzeyde (r=.50, $\mathrm{p}<.01)$; Kolaylaştırıcı durumlar ile Sistem kalitesi arasında pozitif yönde ve orta düzeyde $(\mathrm{r}=.59$, $\mathrm{p}<.01)$; Kolaylaştırıcı Durumlar ile Bilgi Kalitesi arasında pozitif yönde ve orta düzeyde $(\mathrm{r}=.58$, $\mathrm{p}<.01)$; Sosyal Etki ile Sistem Kalitesi arasında pozitif yönde ve düşük düzeyde $(r=.39, p<.01)$; Sosyal Etki ile Bilgi Kalitesi arasında pozitif yönde ve yüksek düzeyde $(r=.76, p<.01)$; Sosyal Etki ile Kolaylaştırıcı Durumlar arasında pozitif yönde ve orta düzeyde ( $r=.53, \mathrm{p}<.01)$; Kullanıcı Memnuniyeti ile Sistem Kalitesi pozitif yönde ve orta düzeyde $(r=.63, p<.01)$; Kullanıc1 Memnuniyeti ile Bilgi Kalitesi arasında pozitif yönde ve yüksek düzeyde (r=.74, p<.01); Kullanıcı Memnuniyeti ile Kolaylaştırıcı Durumlar arasında pozitif yönde ve yüksek düzeyde $(\mathrm{r}=.72$, $\mathrm{p}<.01)$; Kullanıcı Memnuniyeti ile Sosyal Etki arasında pozitif yönde ve yüksek düzeyde (r=.64, $\mathrm{p}<.01)$; Kullanım Bağımlılı̆̆ ile Sistem Kalitesi pozitif yönde ve orta düzeyde $(r=.49, p<.01)$; Kullanım Bağımlılığı ile Bilgi Kalitesi arasında pozitif yönde ve yüksek düzeyde $(r=.73, p<.01)$; Kullanım Bağımlıı̆̆ğ ile Kolaylaştırıcı Durumlar arasında pozitif yönde ve orta düzeyde (r=.47, p<.01); Kullanım Bağımlılı̆̆ ile Sosyal Etki etki arasında pozitif yönde ve yüksek düzeyde $(\mathrm{r}=.72, \mathrm{p}<.01)$. Araştırmanın bağımlı değişkenleri olan Kullanım Bağımlılığı ile Kullanıcı Memnuniyeti arasında ize pozitif yönde ve yüksek düzeyde istatistiksel olarak anlamlı bir ilişki bulunmuştur $(\mathrm{r}=.73, \mathrm{p}<.01)$. Araştırmanın bağımsız değişkenleri ile bağımlı değişkenler olan Kullanım Bağımlılığı ve Kullanıcı Memnuniyeti arasında anlamlı ilişkiler bulunmuştur. Büyüköztürk (2010) bağımsız değişkenlerin bağımlı değişken üzerindeki etkilerini belirlemek amacıyla çoklu regresyon analizi yapılmasını önermektedir. Bu nedenle Kullanıcı memnuniyeti ve kullanım bağımlılığının yordanması amacıyla SK, BK, KD ve SE arasında çoklu regresyon analizi yapılarak sonuçlar Tablo 4'te verilmiştir.

Tablo 4: Kullanıcı Memnuniyeti İçin Çoklu Regresyon Analizi Sonuçları

\begin{tabular}{lccccccc}
\hline Değişken & B & $\begin{array}{c}\text { Standart } \\
\text { Hata }\end{array}$ & B & T & P & $\begin{array}{c}\text { İkili } \\
\text { r }\end{array}$ & $\begin{array}{c}\text { Kısmi } \\
\text { r }\end{array}$ \\
\hline Sabit & $-0,970$ & 1,950 & - & $-0,497$ & .620 & - & - \\
Sistem Kalitesi & 0,116 & 0,046 & 0,167 & 2,537 & .013 & .240 & .127 \\
Bilgi Kalitesi & 0,421 & 0,128 & 0,285 & 3,278 & .001 & .305 & .164 \\
Kolaylaştırıcı Durumlar & 0,185 & 0,049 & 0,275 & 3,796 & .000 & .347 & .190 \\
Sosyal Etki & 0,159 & 0,175 & 0,072 & 0,910 & .365 & .088 & .046 \\
\hline$R=.858 R^{2}=.736$ Düzeltilmiş $R^{2}=.724 \mathrm{~F}(5,105)=58,57$ & $\mathrm{p}=.000$ & & & \\
\hline \multicolumn{7}{l}{}
\end{tabular}


Tablo 4'te SK, BK, KD ve SE'nin Kullanıcı Memnuniyetini yordanmasına ilişkin regresyon analizi sonuçları verilmiştir. Bağımsız değişkenler ile bağımlı değişken arasındaki ikili ve kısmi korelasyonlar incelendiğinde her iki bağımsız değişkenin bağımlı değişken ile pozitif düzeyde ve anlamlı bir ilişki olduğu görülmektedir. Bunun yanında bağımsız değişkenler arasındaki korelasyon katsayısı .80 değerinin altında olduğu için bağımsız değişkenler arasında çoklu bağlantı sorunu olmadığı görülmektedir (Büyüköztürk, 2010, s.100). Regresyon analizi sonuçları incelendiğinde bağımsız değişkenlerden Sosyal Etkinin Kullanıcı Memnuniyetine olan etkisi anlamlı olmayıp, diğer tüm değişkenlerin Kullanıcı Memnuniyetine istatistiksel olarak anlamlı bir etkide bulunduğu görülmektedir $(\mathrm{R}=.858$, $\left.R^{2}=.736, \mathrm{p}<.01\right)$. SK, BK, KD ve SE Kullanıcı Memnuniyeti üzerindeki toplam varyansın \% 74'ü açıklanmaktadır. Standardize edilmiş regresyon katsayısına ( $\beta$ ) göre bağımsız değişkenlerin Kullanıcı Memnuniyeti üzerindeki önem sırası sırasıyla Bilgi Kalitesi, Kolaylaştırıcı Durumlar, Sistem Kalitesi ve Sosyal Etki şeklindedir. Regresyon katsayılarının anlamlığına ilişkin t-testi sonuçları incelendiğinde BK, KD ve SK Kullanıcı Memnuniyeti üzerinde önemli bir yordayıcı olduğu görülmektedir. Araştırmanın bağımsız değişkenlerinin Kullanım Bağımlılığını yordamasına ilişkin regresyon analizi sonuçları Tablo 5'te verilmektedir.

Tablo 5: Kullanım Bağımlılığı İçin Çoklu Regresyon Analizi Sonuçları

\begin{tabular}{lccccccc}
\hline Değişken & B & $\begin{array}{c}\text { Standart } \\
\text { Hata }\end{array}$ & B & T & P & $\begin{array}{c}\text { Íkili } \\
\text { R }\end{array}$ & $\begin{array}{c}\text { Kısmi } \\
\mathrm{r}\end{array}$ \\
\hline Sabit & $-0,306$ & 0,380 & - & $-0,807$ & 0,422 & - & - \\
Sistem Kalitesi & 0,019 & 0,009 & 0,164 & 2,092 & 0,039 & 0,200 & 0,125 \\
Bilgi Kalitesi & 0,078 & 0,025 & 0,324 & 3,137 & 0,002 & 0,293 & 0,187 \\
Kolaylaştırıcı Durumlar & $-0,013$ & 0,009 & $-0,117$ & $-1,360$ & 0,177 & $-0,132$ & $-0,081$ \\
Sosyal Etki & 0,136 & 0,034 & 0,377 & 4,004 & 0,000 & 0,364 & 0,238 \\
\hline$R=.793 R^{2}=.628$ Düzeltilmiş $R^{2}=.610 \mathrm{~F}(5,105)=35,46$ & $\mathrm{p}=.000$ & & & & \\
\hline
\end{tabular}

Tablo 5'te SK, BK, KD ve SE'nin Kullanım Bağımlılı̆̆ını yordamasına ilişkin regresyon analizi sonuçları verilmiştir. Bağımsız değişkenler ile bağımlı değişken arasındaki ikili ve kısmi korelasyonlar incelendiğinde her bir bağımsız değişkenin bağımlı değişken ile pozitif düzeyde ve anlamlı bir ilişki olduğu görülmektedir. Regresyon analizi sonuçları incelendiğinde bağımsız değişkenlerden Kolaylaştırıcı Durumların Kullanım Bağımlığına olan etkisi anlamlı olmayıp diğer tüm değişkenler Kullanıcı Memnuniyetine istatistiksel olarak anlamlı bir etkide bulunduğu görülmektedir $\left(\mathrm{R}=.793, R^{2}=.628, \mathrm{p}<.01\right)$. SK, BK, KD ve 
SE Kullanıcı Memnuniyeti üzerindeki toplam varyansın \% 61 'i açıklanmaktadır. Standardize edilmiş regresyon katsayısına $(\beta)$ göre bağımsız değişkenlerin Kullanım Bağımlılığı üzerindeki önem sırası sırasıyla Sosyal Etki, Bilgi Kalitesi ve Sistem Kalitesi şeklindedir. Regresyon katsayılarının anlamlılığına ilişkin t-testi sonuçları incelendiğinde SE, BK ve SK Kullanım bağımlılığı üzerinde önemli birer yordayıcı olduğu görülmektedir. Araştırma kapsamında modelin test edilmesi amaciyla yapılan korelasyon ve regresyon analizi sonucu elde edilen bulgular Şekil 2'de gösterilmiştir.

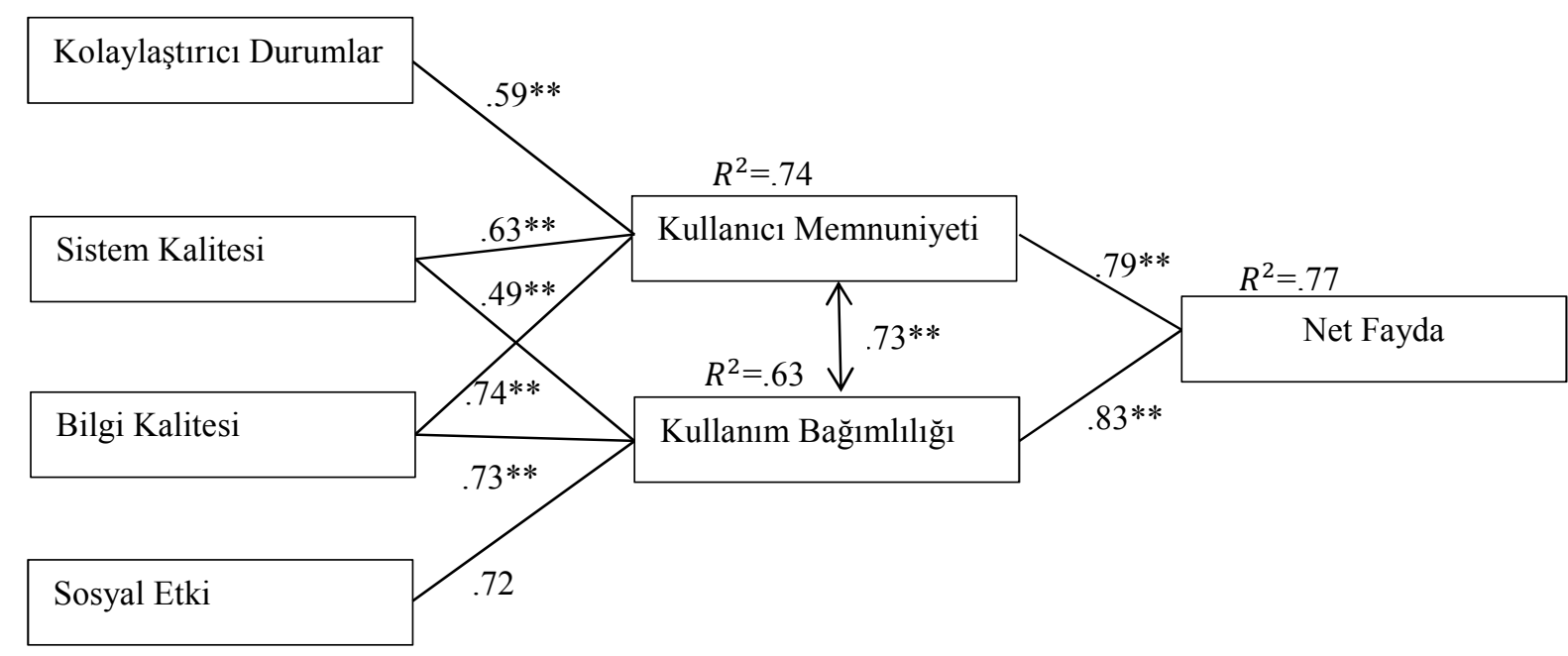

Şekil 2. Test Edilen Model

\section{SONUÇ, TARTIŞMA VE ÖNERILER}

$\mathrm{Bu}$ çalışmanın amacı; e-reçete sistemini kullanan eczane çalışanlarının bilişim sistemleri başarısının ölçümüdür. Bu sistemi ölçmede DeLone ve McLean'in güncellenmiş Bilişim Sistemleri Başarı Modeli (2003) üzerine geliştirilmiş Klinik Bilgi Sistemleri (KBS) Modeli uygulanmıştır. Aydın ilindeki eczane çalışanlarına uygulanan ankette bilgi kalitesi ile sistem kalitesi arasında pozitif yönde, hizmet kalitesi ile sistem kalitesi arasındaki ilişkinin de pozitif yönde fakat orta düzeyde olduğu saptanmıştır. Kolaylaştıııcı durumlar ile Bilgi Kalitesi, Sistem Kalitesi arasındaki ilişkinin pozitif yönde ve orta düzeyde olduğu, Sosyal Etki ve Sistem Kalitesinin de birbirlerini düşük düzeyde etkilediği sonucuna varılmıştır. Smith ve Effken'in (2013) araştırmasında; Bilgi Kalitesi, Sistem Kalitesi ve Kolaylaştırıcı Durumlar, Kullanıcı Memnuniyetini yüksek ölçüde etkilediği ortaya çıkmıştır. Yine aynı çalışmada Bilgi Kalitesi ve Sosyal Etki, Kullanım Bağımlılığını düşük oranda, Kullanıcı Memnuniyeti de Net Faydayı yüksek oranda etkilemektedir.

(DeLone ve McLean'in (2003) genel kabul görmüş modeline göre Sistem Kalitesi de Kullanıc1 Memnuniyetini en önemli faktör olarak destekliyor ve açıklıyor.Çalışmamızda da Kullanıcı Memnuniyeti ile Sistem Kalitesi arasında pozitif yönde ve orta düzeyde, Kullanım Bağımlılığı ile Sistem Kalitesi arasında pozitif yönde ve orta düzeyde anlamlı bir ilişki çıkmıştır. Yine Smith ve 
Effken'in (2013) çalışmalarında Sistem Kalitesiyle Kullanıcı Memnuniyeti, Kullanım Bağımlılığından daha fazla ilişkili çıkmıştır. Ayrıca Kullanım Bağımlılığı ile Kolaylaştırıcı Durumlar arasında pozitif yönde ve orta düzeyde, Sosyal etki ile arasında ise pozitif ve yüksek düzeyde ilişki olduğu belirlenmiştir. Kullanım Bağımlılığı ile Bilgi Kalitesi arasında pozitif yönde ve yüksek düzeyde ilişki olduğu bulunmuştur. Goodhue ve Thompson'ın (1995) çalışmasında da çalışmamızı destekler nitelikte; Bilgi kalitesinin Kullanım Bağımlılığıyla ilişkisinin diğer faktörlerden daha fazla olduğu saptanmıştır.

Sosyal Etkinin Kullanıcı Memnuniyeti üzerindeki etkisi anlamlı bulunmamıştır ve Vencatesh ve David'in (2000) araştırmasına göre de; Sosyal Etkinin daha az etkisi olduğu görülmüştür. Fakat çalışmamızda Kullanım Bağımlılığı Sosyal Etkiyi pozitif ve yüksek düzeyde etkilemektedir. Aynı çalışmada Bilgi Sistemleri ile kullanııların daha fazla tecrübe kazanmasıyla Net Fayda üzerindeki etkisinin daha fazla arttı̆̆ 1 tespit edilmiştir. Kullanıcı Memnuniyeti ile Sistem Kalitesi arasındaki ilişkinin de pozitif yönde çıkması; Aggedilis ve Chatzoglou'nun (2012) çalışmasında da bu çalışmayı destekler nitelikte Sistem Kalitesinin direk ve dolaylı olarak Kullanıcı Memnuniyetini güçlü bir şekilde etkilediği görülmüştür. Hem bu çalışmada hem de kendi çalışmamızda Bilgi Kalitesi de Kullanıcı Memnuniyetini olumlu bir şekilde etkilemektedir.

GrosLovis'in (2005) çalışmalarında da Sistem Kalitesi ve Bilgi Kalitesi ile Kullanıcı Memnuniyetiarasında anlamlı ve birbirine bağlı bir ilişki olduğu ortaya çıkmıştır. Ayrıca araştırmamızın bağımsız değişkenleri olan Kullanıcı Memnuniyeti ile Kullanım Bağımlılığı arasında anlamlı ve pozitif ilişkiler bulunmuştur. Bağımsız değişkenlerden Bilgi Kalitesi, Kullanıcı Memnuniyeti üzerinde en önemli belirleyici faktör iken, Sosyal Etki Kullanıcı Memnuniyetini en düşük düzeyde etkileyen faktör olarak tespit edilmiştir.

Çalışma kapsamında şu önerler sunulmuştur: Sosyal Etki faktörü altında yer alan hizmet desteğive sosyal destek alt faktörlerin boyutlarının yeniden gözden geçirilip gerekirse yeni araştırmalarda bağımsız değişkenler olarak incelenmesi ve bu uygulama yapılırken e-reçete sisteminin aktörlerinden olan doktorların da çalışmaya dahil edilmesi önerilmektedir. Bu çalışmaların ülke bazında genişletilip Türkiye kültürüne yakın dış kültürlere de uygulanabileceği düşünülmektedir.

\section{KAYNAKÇA}

ABDULWAHAB, L., ZULKHAIRI, D. (2010), A Conceptual Model of UnifiedTheory of AcceptanceandUse of Technology(UTAUT) Modificationwith Management Effectivenessand Program Effectiveness in Context of Telecentre, AfricanScientistVol. 11, No. 4, pp: 267-27

AGGEDILİS, P.V, CHATZOGLOU, P.D. (2012), Hospital Information Systems: MeasuringEnd User Computing Satisfaction, Journal of BiomedicalInformatics 45, pp:566-579

BALL, M.J. (2003), Hospital Information Systems: Perspectives on ProblemsandProspects, International Journal of MedicalInformatics, 69, pp:83-89 
BORZEKOWSKİ, R., (2009), Measuringthecostimpact of hospitalinformationsystems: 1987-1994, Journal of HealthEconomics 28 , pp:938-949

CHANG, H.H. (2010), Task-Technology Fit and User Acceptance of Online Auction, InternationalJournal of Human-ComputerStudies,68, pp:69-89

CHEN, R., HSİAO, J. (2011), An Investigation on PhysiciansAcceptance of Hospital Information Systems: A casestudy, International Journal of MedicalInformatics, pp:810-820

DELONE, W.H., MCLEAN, E.R. (1992), Information SystemsSuccess: TheQuestfortheDependentVariable, Inf. Syst. Res. 3 (1), pp: 60-95

DELONE, W.H., MCLEAN, E.R. (2003), TheDeloneandMcLean Model of Information SystemsSuccess: A Ten-YearUpdate,Journal of Management InformationSystems, Cilt:19, Sayı:4, pp:9-30

DOWNING, C. E. (1999), SystemusageBehavior as a Proxy for User Satisfaction: an EmpiricalInvestigation, Information \& Management 35, pp: 203-216, Elsevier

FLOROPOULOS, J., SPATHIS, C., HALVATZIS, D., TSIPOURIDOU, M. (2010), MeasuringtheSuccess of theGreekTaxation Information System, International Journal of Information Management (30), pp:47-56

GELATTI , U.,PEDRAZZANIB, R., MARCANTONIC C., MASCARETTIC, S., REPİCEB, C., FILIPPUCCI, L., ZERBINIA, D.I., DAL GRANDEE, M., ORIZIIOF, G., FERETTİ, D. (2013), You'vegotm@il: Fluoxetinecomingsoon!': Accessibility andquality of aprescriptiondrugsold on the web, International Journal of DrugPolicy, 24, pp:392-401

GOODHUE, D. L., THOMPSON, R. L., (1995), Task-Technology Fit andIndividualPerformance, MIS Quarterly, Volume:19, Issue:2;, pp: 234-236

GROS, D., MUELLER, H., LOVIS, C. (2005),Evaluating User InteractionswithClinical Information Systems: A Model Based on Human-ComputerInteractionModels, Journal of BiomedicalInformatics, Volume:38, pp: 244-255

HONG-SUN, Y.,ZHANG, S. (2013), The Statistical Analysis of Patients' Clinical Data in EmergencyDepartmentby Using Hospital Information System, ScienceDirect,Elsevier, pp:334339

KELLY, B., WELLS, E.B., LECLAİR, AM., TRACY, D., PARSONS, J.T., GOLUB, S.A., (2013), Prevalenceandcorrelates of prescriptiondrugmisuseamongsociallyactiveyoungadults, International Journal of DrugPolicy24, pp: 297-303

KHOKHAR I.,SULTAN, F., AZİZ, M.T., QADRİ,H., ABBAS, M., MUKHTAR, A. MANZOOR, W., YSUF, M.A. (2013),Development of an In-House Hospital Information System in a Hospital in Pakistan, International Journal of MedicalInformatics, pp:1-27

LEHOUX, P., DENIS J. (1999), Assessment of a ComputerizedMedicalRecordSystem: DisclosingScriptstoUse, Evaluation andProgram Planning, vol: 22, pp: 439-53

LİCHTNER, V., VENTERS,W., HİBBERD, R., CORNFORD, T., BARBER, N. (2013), Thefungibility of time in claims of efficiency:Thecase ofmakingtransmissionof prescriptionselectronicin Englishgeneral practice, International Journal of MedicalInformatics, pp: $1-19$

LIU, C.,YANG, P., B, YEH, Y.T., WANG, B.L. (2006), Thermpacts of smartcards on hospitalinformationsystems-an investigationof thefirstphase of thenationalhealthinsurancesmartcard Project in Taiwan, International Journal of MedicalInformatics, 75, pp:173-181

MEIJden, M.J., TANGE, H.J., TROOST J., HASMAN, A. (2003), Determinants of Success of InpatientClinical Information Systems: A LiteratureReview, Journal of Medical Information, 10 (3), pp:235-243 
MOTULSKY, A., LAMOTHE, L., SICOTTE, C. (2013), Impacts of secondgenerationelectronicprescriptions on themedicationmanagementprocess in primarycare:Asystematicreview, International Journal of MedicalInformatics, 82, pp:473-491

ODUKOYA, K., STONE, A., CHUI, M. (2013), How do CommunityPharmaciesRecoverfrom EprescriptionErrors?, Research in Social\&AdministrativeTherapy, pp:1-43

ONG, C.S., LAİ, J-Y. (2007), Measuring User Satisfactionwith Knowledge Management Systems: Scale Development, Purification, andInitial Test, Computersin Human Behavior,(23), pp:13291346

ÖZATA, M., ASLAN, Ş. (2004), Klinik Karar Destek Sistemleri ve Örnek Uygulamalar, Kocatepe Tip Dergisi, 5 pp:11-17

PALVİA, P.C.,PALVİA, S. (1999), An Examination of the IT Satisfaction of Small-Business Users, Information \& Management, Vol. 35, pp. 127-137

PAUL J., PATRICK Y. K. CHAU, O.R., SHENG, L., K. TAM (1999), ExaminingtheTechnologyAcceptance Model Using PhysicianAcceptance of TelemedicineTechnology, Journal of Management Information Systems, Vol. 16, No. 2, pp: 91112

PETTER, S., DELONE, W., MCLEAN, E. (2008), Measuring Information SystemsSuccess:Models, Dimensions, MeasuresandInterrelationships, EuropeanJournal of Information Systems (17), pp:236-263

PETTER, S. FRUHLING. A. (2011), EvaluatingtheSuccess of an EmergencyResponseMedical Information System, International Journal of MedicalInformatics 80, pp: 480-489

PRAYBUTOK, VR (2008), EvaluatingLeadership, IT Quality, and Net Benefits in an e-Government Environment, Information \& Management, Volume 45, Issue 3, pp: 143-152

RAGHAVAN, V., ZHANG, X., ve JEYARAJ, A. (2010),ImplementationSuccess of Clinician Information Systems in Healthcare Contexts, Proceedings, pp:333

ROY, M.C., BOUCHARD, L. (1999), DevelopingandEvaluatingMethodsfor User SatisfactionMeasurement in Practice, Journal of İnformationTechnology Management, Volume:10, Numbers, 3-4, LavalUniversity

SEDDON, P., KİEW, M-Y., (1996),A Partial Test and Development of DeloneandMclean's Model of IS Success, AustralianJournal of Information Systems 4(1), pp: 90-109

SMITH, K., SMITH, V., KRUGMAN, M., OMAN, K., (2005) EvaluatingtheImpact of ComputerizedClinicalDocumentation, CIN: ComputersInformaticsNursingVol. 23, No. 3, pp:132-138

SMITH, D. G.. EFFKEN, J. A. (2013), Development andInitial Evaluation of theClinical Information SystemsSuccess Model (CISSM), International Journal of MedicalInformatics, 82, pp:539-552

SOMERS, T., NELSON, K., KARIMI, J., (2003), ConfirmatoryFactor Analysis of theEnd-User Computing SatisfactionInstrument: Replication within an ERP Domain,DecisionSciences Volume 34 Number 3, pp: 595-615

TOR, H., ERDEN, O. (2004), İlköğretim Öğrencilerinin Bilgi Teknolojilerinden Yararlanma Düzeyleri Üzerine Bir Araştırma, TheTurkish Online Journal of EducationalTechnology volume:3 Issue:1 Article:16

TORKZADEH, G. (1999), The Development of a ToolforMeasuringthePerceivedImpact of Information Technology on Work,Omega, InternationalJournal of ManagementScience, 27, pp:327-339

TORKZADEH, G., DOLL, W.J. (1999), The Development of a ToolforMeasuringthePerceivedImpact of Information Technology on Work,Omega, Int. J. Mgmt. Sci. 27, pp:327-339 
TURAN, A.H., ÇOLAKOĞLU, B. (2008), Yüksek Öğrenimde Öğretim Elemanlarının Teknoloji Kabulü ve Kullanımı: Adnan Menderes Üniversitesinde Ampirik Bir Değerlendirme, Doğuş Üniversitesi Dergisi, Cilt:9, Sayı:1, ss:106-121

VILlLAMAÑÁN, E., HERRERO, A.,SALA, R.A. (2011), TheAssisted Electronic Prescription in Patients in a ChestDiseasesWard,Arch Bronconeumol.;47(3), pp:138-142

VENKATESH, V., MORRIS M. G, DAVIS, G. B \& DAVIS, F. D. (2003), User Acceptance of Information Technology: Toward a UnifiedView, MIS Quarterly, 27(4), pp:425-478

WARHOLAK, T.,RUPP, M., LEAL, S., KURNIAWAN, G., PATEL, N.,(2014), Assessingtheeffect of providing a pharmacistwithpatientdiagnosis on electronicprescriptionorders:A pilot study, Research in SocialandAdministrativePharmacy 10 pp:246-251

WONG, Z. (2011), A ProposedRevisiontotheDeLoneandMcLean's IS SuccessModel,International Conference on E-business, Management andEconomics IPEDR vol.3 , pp:259-261, Press, Hong Kong

YUSUF, Y., GUNASEKARAN, A., ABTHORPE, M. K. (2004), Enterprise Information Systems Project Implementation: A Case study of ERP in Rolls-Royce, International Journal of ProductionEconomics, 87, pp: 251-266

YÜCEL, G., CEBİ, S., HOEGE, B., OZOK, A. (2011), A Fuzzy Risk Assessment Model for Hospital Information System Implementation, An Intemediced Journal, pp:1211-1218

\section{EXTENDED ABSTRACT}

Aim: The purpose of the study is to measure satisfaction levels of pharmacy personnel from eprescription system. We used clinical information systems success model based on the updated information systems success model of DeLone and McLean's (2003). The variables of the model were information quality (IQ), system quality (SYQ), use dependency (UD), user satisfaction (US) social impact (SI), facilitating conditions (FC) and net benefit (NB).

Method: This is a descriptive study. The study used screening models to determine what independent variables and mediating variables explained net benefit perceived by pharmacy personnel towards the system. Pharmacy personnel are one of the users of e-prescribing system which was initiated in Turkey. The study is appropriate for general survey model. Dimensions were determined by a review of the literature. Varimax vertical rotation method was used to determine whether the dimensions were supported by the study group and to determine the factor structure of the measurement tool. Correlation analysis was used to determine whether the variables in 1.and 2. sub-problems were related. Multivariate regression analysis was used to determine to what extent analytical and logical thinking skills independent variables predicted programming success dependent variable. Stepwise regression analysis method was used to determine which independent variables significantly contributed to programming success. To test 4.and 5.sub-problems, whether the data achieved normality and homogeneity assumption was tested. Kolmogorov-Smirnov test was conducted for normality test. The value of ( $p>.05)$ obtained from this test reveals that data is normally distributed in the population. Therefore, we decided to use parametric analysis methods. Levene test was used to determine whether the variance of groups was homogenous. Tukey's test was used in case of homogeneity of variances. Independent sampling t-test was used to compare two groups depending on number of groups. One-way analysis of variance (ANOVA) was used to compare three groups. SPSS 19 software was used for statistical analyses. The population of the study included all pharmacy personnel in Aydin province of Turkey. Participation to the study was voluntary. Necessary approvals were taken from Provincial Directorate of Health and other authorities. A total of 113 questionnaire forms which were properly completed by pharmacists and pharmacy personnel were evaluated. The study was carried out in October-November 2013. 
Result and Suggestions: Factor analysis was conducted using principle components analysis and Varimax vertical rotation method on the obtained data. It was found that 50 items belonged to 7 factors with an eigenvalue greater than 1.00. It was observed that the measurement tool consisted of 7 factors including system quality, information quality, facilitating conditions, social impact, user satisfaction, use dependency and net benefit. We found that $56.92 \%$ of total variance was explained by the variables. High variance level obtained from factor analysis indicates robust factor structure of the scale. Factor structure of test items was found to be consisted with previous studies in the literature. Pearson's Correlation Coefficients were calculated to determine the relationships between the latent variables of the study to test the model developed by the researchers. It was found that all relationships between the independent variables were significant at .01 level. Independent variables were determined as system quality (SQ) information quality (IQ), facilitating conditions (FC) and social impact (SI). On the other hand, since independent variables were considered to affect user satisfaction (US) and use dependency (UD), these variables were determined to be dependent variables of the study. Developed model was used to test to what degree user satisfaction and use dependency affected net benefit. The fact that correlation coefficient between the independent variables was smaller than .90 indicates that there is no multicollineary problem between the variables (Büyüköztürk, 2010). We found a positive and moderate relationship between IQ and SYQ $(\mathrm{r}=.50, \mathrm{p}<.01)$; a positive and moderate relationship between FC and SYQ $(\mathrm{r}=.59, \mathrm{p}<.01)$; a positive and moderate relationship between FC and IQ $(\mathrm{r}=.58, \mathrm{p}<.01)$; a positive and low relationship between SI and SYQ $(\mathrm{r}=.39$, $\mathrm{p}<.01)$; positive and significant relationship between SI and IQ $(\mathrm{r}=.76, \mathrm{p}<.01)$; a positive and moderate relationship between SI and $\mathrm{FC}(\mathrm{r}=.53, \mathrm{p}<.01)$; a positive and moderate relationship between US and SYQ $(r=.63, p<.01)$; a positive and significant relationship between US and IQ $(r=.74, p<.01)$; a positive and significant relationship between US and $\mathrm{FC}(\mathrm{r}=.72, \mathrm{p}<.01)$; a positive and significant relationship between US and SI $(\mathrm{r}=.64, \mathrm{p}<.01)$; a positive and moderate relationship between use dependency and SYQ $(\mathrm{r}=.49, \mathrm{p}<.01)$; a positive and significant relationship between use dependency and IQ $(\mathrm{r}=.73, \mathrm{p}<.01)$; a positive and moderate relationship between use dependency and $\mathrm{FC}(\mathrm{r}=.47$, $\mathrm{p}<.01)$; a positive and significant relationship between use dependency and SI $(\mathrm{r}=.72, \mathrm{p}<.01)$. We found significant relationships between independent variables and use dependency and user satisfaction dependent variables of the study. Results of regression analysis revealed that social impact independent variable did not significantly affect user satisfaction, however all other variables significantly affected user satisfaction $\left(\mathrm{R}=.858, R^{2}=.736, \mathrm{p}<.01\right)$. SYQ, IQ, FC and SI explained $74 \%$ of total variance on US. According to standardized regression coefficient ( $\beta$ ), US was mostly affected by IQ, FC, SYQ and SI respectively. T-test results on the significance of regression coefficients revealed that IQ, FC and SYQ were significant predictors of US.

Suggestions: Service support and social support sub-dimensions under social impact factor should be reviewed and, if necessary, examined as independent variables in future studies. Furthermore, as other actors of e-prescription system, physicians should also be included in studies. We believe that this study can be extended on country basis and can also be applied by other cultures that have a similar culture to that of Turkey. 